\title{
Size and Composition of Foraging Flights in Two Species of Piscivorous Colonial Birds: Limited Evidence for Intra- or Interspecific Information Transfer
}

\author{
Jennifer L. Doucette, Victoria A. Kjoss, and Christopher M. Somers* \\ Department of Biology, University of Regina, 3737 Wascana Pkwy, Regina, Saskatchewan, Canada, S4S 0A2
}

\begin{abstract}
Colonial birds must derive benefits from living in conspecific groups and with other species. One possible benefit is that they follow previously successful individuals to foraging sites (information center hypothesis). To test for evidence of intra- and interspecific information transfer, we assessed the group size and composition of flights of doublecrested cormorants (Phalacrocorax auritus) and American white pelicans (Pelecanus erythrorhynchos) at two mixed colonies. Flights by solo individuals were the most common outbound type, suggesting that the birds do not immediately follow others. However, the majority of the total number of outbound birds traveled in groups. In comparison, groups inbound to colonies and flying between feeding locations were large. Regardless of flight direction, groups were almost always largest during the late chick-rearing period. This suggests that groups may have some function, although likely not to share information about foraging-sites. Mixed-species groups in general were rare, so it is unlikely that these birds commonly locate prey by following other species in flight.
\end{abstract}

\section{INTRODUCTION}

Colonial birds face trade-offs associated with group living: the potential costs of increased competition for resources and transmission of parasites and disease [1], versus the potential benefits of decreased predation [2, 3] (but see [4]) and the transfer of information regarding foraging success, whereby the colony serves as an information center [5]. As part of an information center, birds in breeding colonies may benefit from following successful individuals to good foraging sites. Information about food supplies could be especially important for colonial birds that often travel long distances and must find patchy or ephemeral food sources, such as schools of fish in large bodies of water. Piscivorous birds are often colonial (98\% of seabirds are colonial [6]), so part of the importance of breeding colonies may be to share information, either willingly or through parasitism, about the location and availability of prey [5,7].

American white pelicans (Pelecanus erythrorhynchos; hereafter, pelicans) and double-crested cormorants (Phalacrocorax auritus; hereafter cormorants) are social, colonial breeding birds. Both species nest in dense aggregations and forage in groups with conspecifics whereby flocks appear to drive schools of fish, increasing individual success [8-10]. The benefit of increased success at capturing prey likely encourages group formation at foraging sites; however, it is unknown whether foraging aggregations are initiated at the breeding colony as part of an information center system, or via another mechanism that may be independent of colonial breeding. Pelicans could benefit from following others from

*Address correspondence to this author at the Department of Biology, University of Regina, 3737 Wascana Pkwy, Regina, Saskatchewan, Canada, S4S 0A2; Tel: 306-585-4850; Fax: 306-337-2410;

E-mail: chris.somers@uregina.ca the colony because of the long interval between incubation changeovers [e.g., 11], during which time prey fish may be depleted or move to new locations. Also, pelicans travel great distances (up to $600 \mathrm{~km}[12,13]$ ) to forage; thus, information about foraging success may be critical for deciding how to best allocate this effort. However, following other pelicans from the colony may not be selected for because all nesting pelicans forage infrequently due to similarly long intervals between incubation changeovers or chick feedings [11]. Previous studies examining flock formation in pelicans found that outbound groups do form as birds leave colonies, but suggested that this behaviour was more likely to facilitate group foraging at the destination, rather than the transfer of information at the colony $[11,14]$.

The pelicans previously studied [11, 14] were from a single colony and no other species were considered; to our knowledge, no studies have investigated double-crested cormorants in the context of group formation and information transfer, although groups do form in flight [15], and group foraging is a successful strategy for great cormorants (P. carbo sinensis) [10]. Recent evidence suggests that information can also be passed between species [16]. Pelicans commonly nest with double-crested cormorants throughout much of their range [17-19], and thus may benefit by following cormorants to foraging sites. Cormorants make more frequent foraging trips than pelicans [20], and thus would be more likely to have current information regarding the location of ephemeral fish prey. In addition, we have commonly observed mixed flocks of pelicans and cormorants foraging in the same locations (Fig. 1a), and moving together to and from foraging sites (Fig. 1b), indicating that these species often associate away from breeding colonies [8, 21]. In addition, some studies have indicated that pelicans and cormor- 
a.

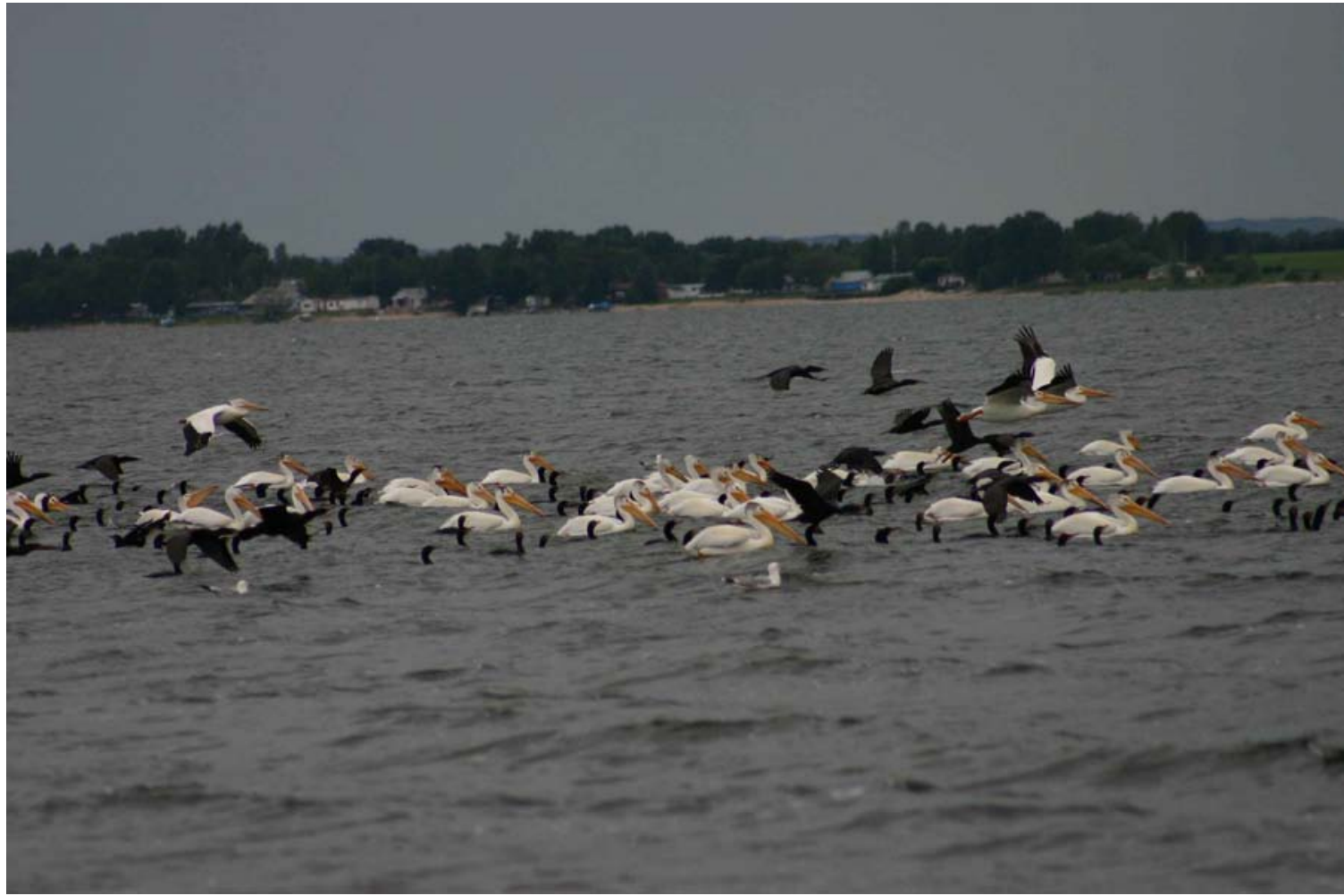

b.

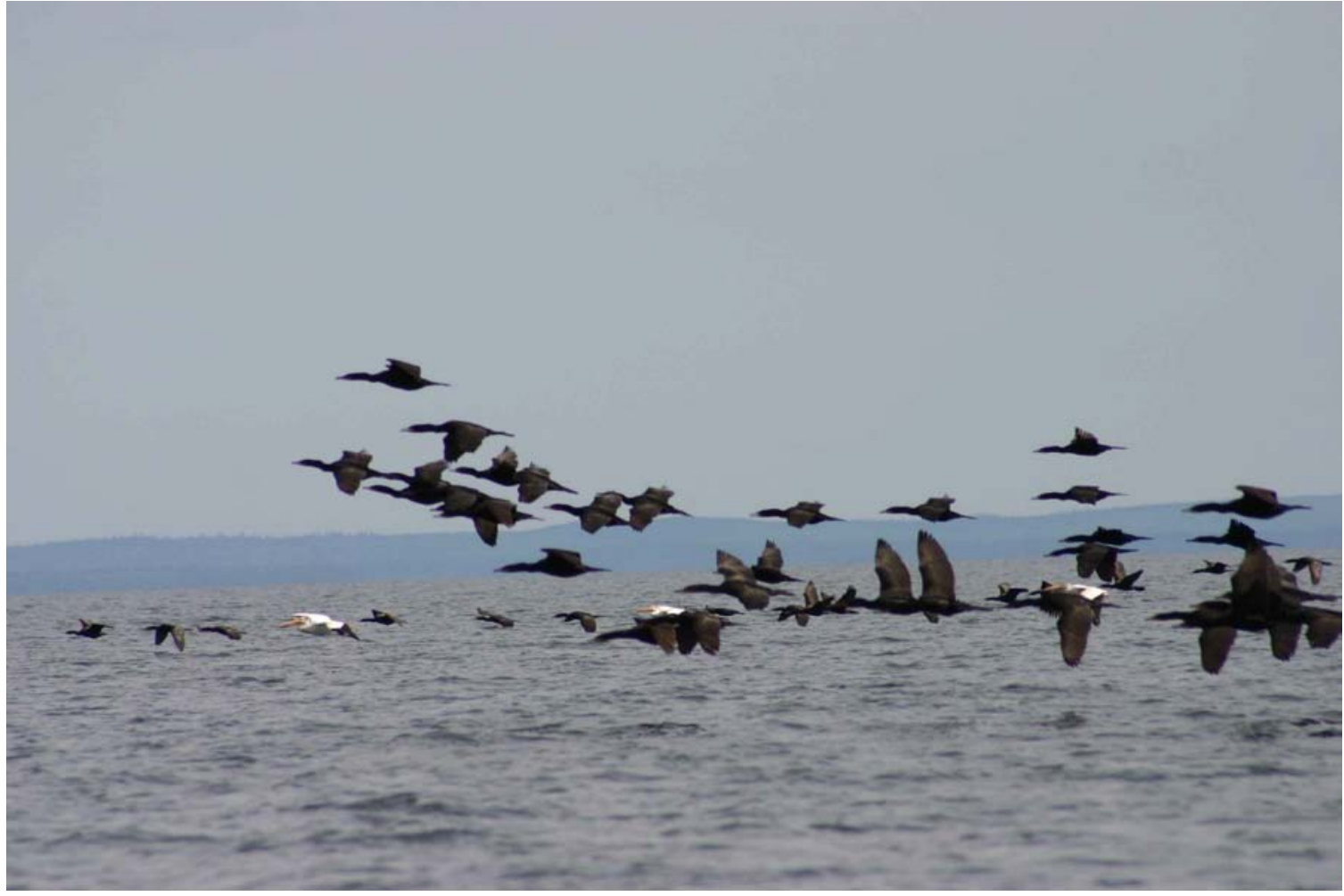

Fig. (1). Mixed groups of double-crested cormorants and American white pelicans (a) foraging on Last Mountain Lake and (b) moving among foraging sites (i.e., in transit) on Dore Lake.

ants from shared colonies consume similar prey species ([22]; C. Somers et al. unpublished data). It is therefore possible that pelicans and cormorants in shared breeding colonies may benefit from both intra- and interspecific informa- tion transfer, and in particular pelicans may benefit from the presence of cormorants due to differences in foraging trip frequency, and the possibility that cormorants flush prey to the surface while diving. 
We hypothesized that breeding colonies serve as both intra- and interspecific information centers for pelicans and cormorants nesting on large lakes in Saskatchewan, Canada. To test this hypothesis, we examined group size and composition of pelican and cormorant flights exiting (outbound) and returning (inbound) to colonies, as well as those flying at sites removed from breeding colonies. If birds use an information center system, we predicted that both single-species and mixed groups would form at colonies, and that outbound groups heading to foraging sites would be larger than inbound groups. In addition, we predicted that pelicans would attempt to follow cormorants (i.e., cormorants should lead mixed-species groups) to take advantage of current information about prey availability.

\section{MATERIALS AND METHODOLOGY}

\section{Study Sites}

1) Last Mountain Lake $\left(51^{\circ} 20 ' \mathrm{~N}, 105^{\circ} 15^{\prime} \mathrm{W}\right)$ is a long, narrow, eutrophic lake with a surface area of approximately $233 \mathrm{~km}^{2}$. It is located in the mixed-grass prairie region of southern Saskatchewan and is surrounded by a mosaic of native grasslands, agricultural fields, and small towns. The lake has a mean depth of $7.6 \mathrm{~m}$ (maximum $31.5 \mathrm{~m}$ ) and exhibits diverse habitats, including shallow wetlands, rocky shorelines, and islands. Cormorants and pelicans nest at the north end of the lake in the Last Mountain Lake National Wildlife Area and Migratory Bird Sanctuary. In 2007, approximately 1,500 pelican and 1,600 cormorant pairs nested in a shared colony on a $\sim 1$-ha island.

2) Dore Lake $\left(54^{\circ} 46^{\prime} \mathrm{N}, 107^{\circ} 17^{\prime} \mathrm{W}\right)$ is located in the boreal plain region of central Saskatchewan. This remote, mildly eutrophic lake is in a wilderness area surrounded by mixed aspen, pine, and spruce forest. The $616-\mathrm{km}^{2}$ water body has a mean depth of $11.2 \mathrm{~m}$ (maximum 19.5 $\mathrm{m})$ and contains a number of islands. Habitats include wetlands, shallow bays with emergent vegetation, rocky substrates, and sand beaches. A large portion of the lake is pelagic, open water. Dore Lake supports approximately 11,500 breeding pairs of cormorants and 2,000 pairs of pelicans on two breeding islands. The colony we studied consisted of approximately 9,000 pairs of cormorants and 1,700 pairs of pelicans on a 3 -ha island in the southwest portion of the lake.

\section{Composition and Size of Flights at Breeding Colonies}

At Last Mountain Lake, we recorded inbound and outbound flights from all directions simultaneously, whereas at Dore Lake we focused on flights around the northern half of the breeding island. This modification at Dore Lake was necessary because of frequent flights associated with the very large breeding colony there. We simultaneously recorded the size and composition of inbound and outbound flights from both colonies continuously for 30-minute observation periods. A minimum of two observers (one person per direction) conducted two to ten observation periods per day. For mixed-species groups, we counted the number of pelicans and cormorants making up the groups and identified the species leading the flight. We considered two or more individuals to constitute a group when they were moving to- gether along the same trajectory and were separated by a maximum of 5 seconds of flying time.

The sizes of incoming groups were noted as soon as they were within sight and monitored for changes as they approached the colony. Groups that joined together within sight of the colony were recorded separately. Similarly, individuals that joined incoming flights within sight of the colony were not considered to be part of larger groups. All outgoing flights that lifted off from the colony during the session and flew out of sight were counted. Flights were only counted once their flight trajectory appeared set, and birds that joined outgoing flights were added according to our 5 second definition.

At Last Mountain Lake, flights at the colony were observed during 129 30-minute observation periods between 5 May and 23 July 2007. Flights were observed using $12 \times 50$ $\mathrm{mm}$ binoculars from the nearest shoreline, approximately $800 \mathrm{~m}$ from the colony. At Dore Lake, 126 30-minute observation sessions were conducted between 19 May and 8 August 2007. Flights were observed from a neighboring island approximately $600 \mathrm{~m}$ away, and for the most part did not require the use of binoculars. When necessary, flights were observed using $8 \times 42$-mm binoculars.

\section{Composition and Size of Flights in Transit}

We characterized groups that were moving among foraging areas (in transit) at locations removed from the breeding colony. At Last Mountain Lake, we observed transit flights during 2-5-minute point counts conducted at six shoreline locations ranging from 3 to $30 \mathrm{~km}$ from the colony. We recorded the size and composition of all flights using the same criteria for groups described above. The size of Dore Lake and minimal road access prevented use of a similar shoreline point count system. Instead, transit flights were characterized from a boat while traveling the same $\sim 14-\mathrm{km}$ route from the boat launch to and from the breeding colony. All flights that could be seen from the boat were recorded using the same criteria described above. We did not count transit flights observed within $3 \mathrm{~km}$ of the colony. Flight direction was not recorded for any flights in transit.

\section{Statistical Analyses}

We compared the frequency of occurrence of inbound, outbound, and transit flights in four group size classes: 1, $2-$ $5,6-9, \geq 10$ individuals for single-species flights, and 2, 3-5, $6-9, \geq 10$ individuals for mixed groups, using chi-squared contingency table analysis. We also compared the total number of birds flying alone (solo) to those in groups using a similar chi-squared analysis. For analysis of group size, we divided the breeding season into three periods: 1) eggincubation (1-31 May), 2) early chick rearing (1-30 June), and 3) late chick rearing (1 July - mid-August). We used a 2 -factor analysis of variance to compare the effects of nesting period and flight direction on log-transformed group size for each flight type (pelicans, cormorants, and mixed species groups). Group size data for each lake were log-transformed to meet assumptions of homoscedasticity; however, no transformation normalized the residuals (determined using the Wilks-Shapiro test). Visual inspection of the distribution of residuals indicated a similar near-conformation to normality 
among datasets, so we used a parametric ANOVA. Tests were conducted using Statistix 9.0 and Statistica 8.0 with an alpha value of 0.05 .

\section{RESULTS}

\section{Composition and Size of Flights}

\section{Last Mountain Lake}

We observed 10,445 flights at the Last Mountain Lake colony, of which 9160 (82.9\%) were cormorant-only, 1767 $(14.7 \%)$ were pelican-only, and $261(2.4 \%)$ were mixed flocks (Table 1). The frequency of pelican flights in four group size categories differed based on whether flights were inbound, outbound, or in transit (Table 1; $X^{2}=40.74, \mathrm{df}=6$, $\mathrm{P}<0.001)$. Most of the chi-squared value was generated by more outbound solo flights $(63 \%)$ and more non-solo inbound flights than expected (Table 1). When expressed as the total number of birds moving rather than as flight frequency, the number of pelicans flying solo differed based on whether the flights were inbound, outbound, or in transit $\left(X^{2}=105.28, \mathrm{df}=2, \mathrm{P}<0.001\right)$. Of 1,536 outbound pelicans, $552(36 \%)$ flew solo, compared to 343 of 1,515 (23\%) inbound and 115 of $653(18 \%)$ observed in transit. Thus, although more flights to or from the colony were single individuals rather than groups, a higher percentage (64-82\%) of the total number of birds observed moving belonged to groups.

Similar to pelicans, the frequency of cormorant flights in the four different group size categories differed based on flight type (inbound, outbound, or in transit; Table 1;
$\left.X^{2}=286.31, \mathrm{df}=6, \mathrm{P}<0.001\right)$. Most of the chi-squared value was generated by more solo outbound cormorant flights $(63 \%)$ than all other group size categories combined, fewer inbound solo flights, and more inbound flights with group sizes of $6-9(7 \%)$ and $\geq 10$ individuals $(4 \%)$ than expected. In transit, more flights had $\geq 10(5 \%)$ individuals, and we observed more solo flights than expected. When expressed as the total number of birds moving, the number of cormorants flying solo differed based on whether the flights were inbound, outbound, or in transit $\left(X^{2}=802.87, \mathrm{df}=2, \mathrm{P}<0.001\right)$. Of 8,501 outbound cormorants, 3,083 (36\%) flew solo, compared to 1,938 of 9,707 (20\%) inbound, and 294 of 2,100 $(14 \%)$ in transit. Similar to pelicans, cormorant flights were most often solo individuals, but a higher percentage of the total number of birds observed (64-86\%) belonged to groups.

In contrast to single-species flights, we found no difference in the frequency of mixed-species flights in the four group size categories (Table $\mathbf{1} ; X^{2}=10.74$, $\mathrm{df}=6, \mathrm{P}=0.096$ ). However, this analysis was limited by a low sample size and should be interpreted with caution. The most common mixed group size for all flight types at Last Mountain Lake was 3-5 birds (Table 1). There were more in-transit mixed flights containing $\geq 10$ individuals $(31 \%)$ than both inbound $(6 \%)$ and outbound $(7 \%)$ flights at the breeding colony. When expressed as the number of individuals moving, 206 of 753 $(41 \%)$ outbound and 157 of $354(44 \%)$ inbound birds traveled in groups of 3-5 individuals, whereas 178 of $218(83 \%)$ in-transit birds traveled in groups of $\geq 10$ individuals. Cormorants on average made up the largest proportion of mixedspecies groups both inbound $(0.52 \pm 0.20)$ and outbound

Table 1. The Number of Observed Flights in Four Group Size Categories for Pelicans, Cormorants, and Mixed-Species Groups at Last Mountain Lake During 2007. Counts of Inbound and Outbound Flights were Made at Breeding Colonies, Whereas In-Transit Flights were Observed in Foraging Areas

\begin{tabular}{|c|c|c|c|c|c|c|}
\hline \multirow{2}{*}{ Composition } & \multirow{2}{*}{$\begin{array}{c}\text { Flight } \\
\text { Type }\end{array}$} & \multicolumn{4}{|c|}{ Frequency of Group Size } & \multirow{2}{*}{ Total } \\
\hline & & 1 & 2 to 5 & 6 to 9 & $\geq 10$ & \\
\hline \multirow{3}{*}{ Pelicans } & Inbound & 343 & 270 & 30 & 15 & 658 \\
\hline & Outbound & 552 & 296 & 21 & 6 & 875 \\
\hline & Total & 1010 & 664 & 61 & 32 & 1767 \\
\hline \multirow{3}{*}{ Cormorants } & Inbound & 1938 & 1464 & 250 & 136 & 3788 \\
\hline & Outbound & 3083 & 1659 & 107 & 27 & 4876 \\
\hline & Transit & 294 & 161 & 17 & 24 & 496 \\
\hline \multirow{4}{*}{ Mixed } & Inbound & 21 & 42 & 13 & 5 & 81 \\
\hline & Outbound & 43 & 83 & 30 & 11 & 167 \\
\hline & Transit & 3 & 4 & 2 & 4 & 13 \\
\hline & Total & 67 & 129 & 45 & 20 & 261 \\
\hline
\end{tabular}


$(0.59 \pm 0.19)$ from the colony, and led the majority of inbound $(67 \%)$ and outbound $(64 \%)$ mixed flights. In contrast, flights in transit had a larger proportion of pelicans $(0.61 \pm 0.24)$ and were most often led by pelicans $(62 \%)$.

\section{Dore Lake}

We observed 54,854 flights at the Dore Lake colony, of which 51,631 (93.2\%) were cormorant-only groups, 2,821 $(5 \%)$ were pelican-only groups, and 971 (1.8\%) were mixedspecies groups (Table 2 ). The frequency of pelican groups in the four size categories differed based on whether flights were inbound, outbound, or in transit (Table 2; $X^{2}=27.47$, $\mathrm{df}=6, \mathrm{P}<0.001)$. Solo outbound pelican flights were more frequent than expected (73\%; Table 2). In-transit pelican flight sizes were similar to the expected values, with the majority of flights being solo (73\%), and no groups containing $\geq 10$ individuals. The total number of pelicans flying solo differed based on whether the flights were inbound, outbound, or in transit $\left(X^{2}=74.85, \mathrm{df}=2, \mathrm{P}<0.001\right)$. Of 2,624 outbound pelicans, 1,262 (48\%) flew solo, compared to 707 of $1,990(36 \%)$ inbound, and 43 of $86(50 \%)$ in transit. Thus, pelican flights tended to be solo, although at least half of the birds moving to and from the colony or in transit did so in groups.

The frequency of cormorant flights in four group size categories differed based on whether flights were inbound, outbound, or in transit (Table $2 ; X^{2}=739.07, \mathrm{df}=6, \mathrm{P}<0.001$ ). Solo flights were the most frequent at the colony and in transit (inbound, 48\%; outbound, 50\%; in transit, 51\%). Outbound groups consisted mainly of 1-5 individuals and included more solo flights than expected (Table 2). Larger inbound and in-transit flights (size categories 6-9 and $\geq 10$ ) were also more frequent than expected. In-transit cormorant flights included more solo events than expected, but there was also a greater proportion of groups containing $\geq 10$ birds $(12 \%)$ than inbound $(8 \%)$ or outbound $(3 \%)$ flights. The total number of birds flying solo differed based on whether the flights were inbound, outbound, or in transit $\left(X^{2}=1719.3\right.$, $\mathrm{df}=2, \mathrm{P}<0.001) ; 14,523$ of 75,237 (19\%) outbound birds flew solo compared to 10,639 of $87,491(12 \%)$ inbound and 259 of $3,179(8 \%)$ in transit. Thus, while solo flights were frequent, the majority of cormorants $(81-92 \%)$ traveled in groups.

In contrast to Last Mountain Lake, the frequency of mixed-species flights in the four group size categories at Dore Lake differed based on whether flights were inbound, outbound, or in transit (Table $2 ; X^{2}=29.64, \mathrm{df}=6, \mathrm{P}<0.001$ ). Similar to the single-species flights, outbound mixed groups were smaller than expected, and inbound mixed flights had a greater frequency of groups containing $\geq 10$ individuals $(27 \%)$ than expected. In contrast, all in-transit mixed flight groups contained $\geq 10$ individuals, although only three mixed in-transit groups were observed (Table 2). Of the 3,636 total inbound birds in mixed groups, $2,628(72 \%)$ were in groups of $\geq 10$ individuals, and all birds observed in transit flew in groups of $\geq 10$ individuals. In comparison, 2,106 of 4,351 $(48 \%)$ birds in outbound mixed flights were in these larger groups. Mixed-species flights consisted of proportionally more cormorants during inbound $(0.66 \pm 0.22)$ and outbound $(0.66 \pm 0.19)$ flights at the colony, as well as in transit $(0.92 \pm 0.04)$. Outbound mixed groups had more cormorant leaders (0.62), as did in-transit groups (0.67). However, un-

Table 2. The Number of Observed Flights in Four Different Group Size Categories for Pelicans, Cormorants, or Mixed-Species Groups at Dore Lake During 2007. Counts of Inbound and Outbound Flights were Made at Breeding Colonies, Whereas In-Transit Flights were Observed in Foraging Areas

\begin{tabular}{|c|c|c|c|c|c|c|}
\hline \multirow{2}{*}{ Composition } & \multirow{2}{*}{$\begin{array}{c}\text { Flight } \\
\text { Type }\end{array}$} & \multicolumn{4}{|c|}{ Frequency of Group Size } & \multirow{2}{*}{ Tota } \\
\hline & & 1 & 2 to 5 & 6 to 9 & $\geq 10$ & \\
\hline \multirow{3}{*}{ Pelicans } & Inbound & 707 & 276 & 32 & 20 & 1035 \\
\hline & Outbound & 1262 & 434 & 23 & 8 & 1727 \\
\hline & Total & 2012 & 725 & 56 & 28 & 2821 \\
\hline \multirow{3}{*}{ Cormorants } & Inbound & 10639 & 8196 & 1600 & 1824 & 22259 \\
\hline & Outbound & 14523 & 11788 & 1627 & 925 & 28863 \\
\hline & Transit & 259 & 153 & 38 & 59 & 509 \\
\hline \multirow{4}{*}{ Mixed } & Inbound & 74 & 107 & 60 & 87 & 328 \\
\hline & Outbound & 154 & 260 & 126 & 100 & 640 \\
\hline & Transit & 0 & 0 & 0 & 3 & 3 \\
\hline & Total & 228 & 367 & 186 & 190 & 971 \\
\hline
\end{tabular}


like at Last Mountain Lake, pelicans and cormorants at Dore Lake both led inbound mixed groups approximately equally ( $51 \%$ and $49 \%$, respectively).

\section{Sizes of Flights at Breeding Colonies}

\section{Last Mountain Lake}

Pelican group size varied by nesting period (Fig. 2a; ANOVA, $\left.F_{2,1527}=13.40, \mathrm{P}<0.001\right)$. Post-hoc comparisons indicated that pelican groups, regardless of direction, were larger during the late chick-rearing period $(2.43 \pm 2.80)$ than during egg incubation $(1.79 \pm 1.75)$ and early chick rearing $(1.89 \pm 1.54)$. Pelican group size also varied with flight direction $\left(\mathrm{F}_{1,1527}=34.95, \mathrm{P}<0.001\right)$. Inbound groups were on average 1.3 times larger $(2.30 \pm 2.51)$ than outbound $(1.76 \pm 1.54$; Fig. 2a). There was no interaction between nest period and flight direction with pelican group size $\left(\mathrm{F}_{2},{ }_{1527}=2.20\right.$, $\mathrm{P}=0.11$ ), indicating that inbound flights were consistently larger than outbound flights across the breeding season.

Cormorant group size also varied by nesting period (Fig 2b; $\left.\mathrm{F}_{2,8658}=146.13, \mathrm{P}<0.001\right)$. However, in contrast to pelicans nesting in the same colony, post-hoc testing showed that group sizes were larger during the early chick-rearing period $(2.58 \pm 2.92)$ than during egg incubation $(1.86 \pm 1.81)$ or late chick rearing $(1.82 \pm 2.02)$. Group size also varied with flight direction (Fig. 2b; $\mathrm{F}_{1,8658}=303.72, \mathrm{P}<0.001$ ), whereby inbound groups were on average 1.5 times larger $(2.56 \pm 3.02)$ than outbound $(1.74 \pm 1.51)$. Also different from pelicans at the same location, there was an interaction between period and flight direction for cormorants $\left(\mathrm{F}_{2,8658}=15.42, \mathrm{P}<0.001\right)$. Inbound flight groups were larger during the early chickrearing period $(3.28 \pm 3.74)$ than all other groups. Outbound flights during the late chick-rearing period were the smallest (1.46 \pm 1.06$)$, followed by outbound flights during egg incubation (1.66 \pm 1.29$)$.

Unlike single-species groups, mixed-species group sizes at Last Mountain Lake did not vary with nesting period or flight direction (Fig. 2c; $F_{2,242}=2.12, P=0.122 ; F_{1,242}=0.10$, $\mathrm{P}=0.749$ ), and there was no interaction between these two variables $\left(\mathrm{F}_{2}, 242=0.81, \mathrm{P}=0.445\right)$. Thus, mixed-species groups at Last Mountain Lake were consistent in size during the whole breeding season and regardless of direction.

\section{Dore Lake}

Pelican flights varied in size by nesting period (Fig. 3a; $\left.\mathrm{F}_{2,2756}=18.96, \mathrm{P}<0.001\right)$. Similar to Last Mountain Lake, post-hoc comparisons revealed that groups were larger in the late chick-rearing period $(1.92 \pm 2.46)$ than during egg incubation $(1.47 \pm 1.17)$ or early chick rearing $(1.47 \pm 1.28)$. Pelican group sizes also varied by flight direction (Fig. 3a; $F_{1,2756}=$ $18.675, \mathrm{P}<0.001)$; inbound groups were on average 1.3 times larger $(1.92 \pm 2.59)$ than outbound groups (1.52 \pm 1.29$)$. There was no interaction between nest period and flight direction $\left(\mathrm{F}_{2}, 2756=1.054, \mathrm{P}=0.348\right)$, indicating that inbound flights were consistently larger than outbound flights across the breeding season.

Cormorant group size also varied with nest period (Fig. 3b; $\left.\mathrm{F}_{2,6079}=1388, \mathrm{P}<0.001\right)$. Post-hoc comparisons showed that group size was largest during the late chick-rearing period (4.73 \pm 9.96$)$, and smallest during egg incubation $(1.90 \pm 1.83)$. Cormorant flight sizes also varied by flight di- rection $\left(\mathrm{F}_{1,6079}=540, \mathrm{P}<0.001\right)$; inbound groups were on average 1.5-times larger $(3.83 \pm 8.10)$ than outbound $(2.61 \pm$ 3.96). There was a significant interaction between nest period and flight direction $\left(\mathrm{F}_{2},{ }_{6079}=6, \mathrm{P}=0.005\right)$. Pair-wise comparisons revealed differences between all periods and directions, with one exception: inbound flights during early chick rearing $(3.56 \pm 4.07)$ were similar to outbound flights during late chick rearing $(3.64 \pm 6.14)$.
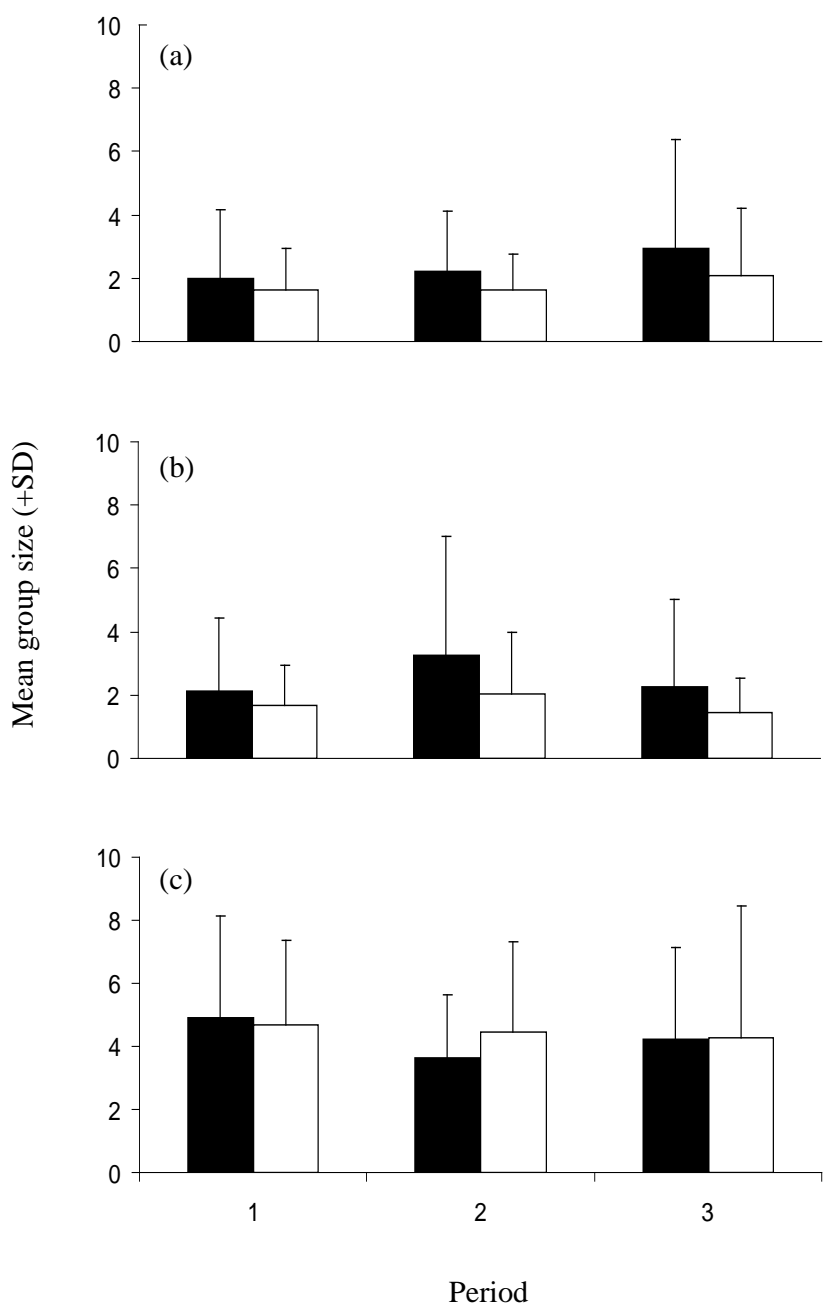

Fig. (2). Mean group size (+SD) of (a) American white pelicans, (b) double-crested cormorants, and (c) mixed-species groups at Last Mountain Lake in 2007. Inbound (black bars) and outbound (open bars) flights at the colony are divided into three periods: egg incubation (1), early chick rearing (2), and late chick rearing (3). Statistical relationships are described in the text.

Mixed-species groups varied in size with nesting period on Dore Lake (Fig. 3c; $F_{2,962}=80.73, \mathrm{P}<0.001$ ). Post-hoc testing revealed that group size in all three periods was different; the smallest group sizes were observed during the egg-incubation period $(3.93 \pm 3.14)$ and the largest were observed during late chick rearing (13.04 18.99$)$. We also noted an effect of flight direction $\left(\mathrm{F}_{1,962}=25.24, \mathrm{P}<0.001\right)$; inbound groups were on average 1.6 times larger $(11.05 \pm .20)$ than outbound groups $(6.80 \pm 8.38)$. Nest period and direction had a significant interaction $\left(\mathrm{F}_{2,962}=4.45, \mathrm{P}=0.012\right)$, driven by much larger inbound flights during late chick rearing $(21.01 \pm 28.97)$ than any other time. Outbound flights during 
early chick rearing were also larger $(4.87 \pm 7.32)$ than flights during egg incubation, but were on average 1.8 times smaller than inbound flights during the same period $(8.78 \pm 9.82)$ and 2.7 times smaller than all flights during late chick rearing (13.04 \pm 18.99$)$.
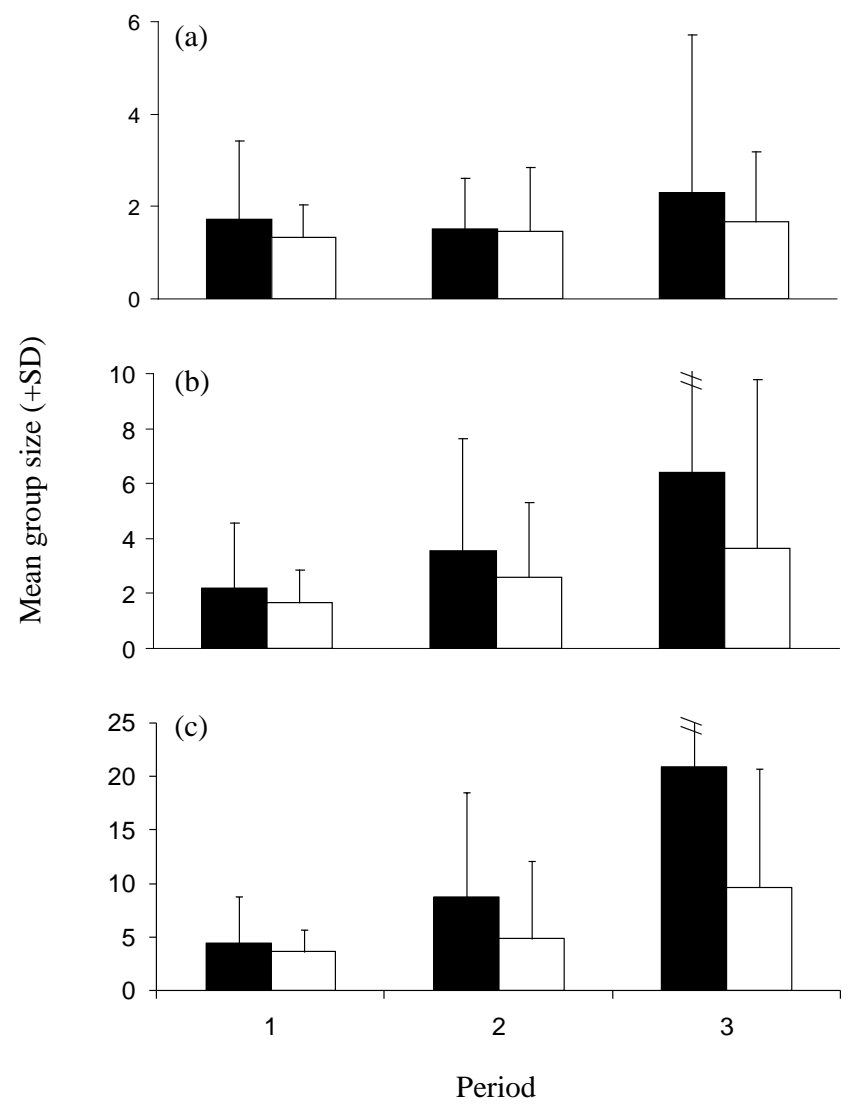

Fig. (3). Mean group size (+SD) of (a) American white pelicans, (b) double-crested cormorants, and (c) mixed groups during 2007 at Dore Lake. Inbound (black bars) and outbound (open bars) flights at the colony are divided into three periods: egg incubation (1), early chick rearing (2), and late chick rearing (3). Statistical relationships are described in the text; the error bars on inbound flights in panels (b) and (c) for period 3 are truncated to keep the y-axis scales within a reasonable range for display.

\section{DISCUSSION}

We hypothesized that breeding colonies serve as centers for intra- and interspecific information transfer about foraging success for cormorants and pelicans nesting on two large lakes in Saskatchewan. Under this hypothesis, we made two major predictions: (1) groups should form at the colony so that naïve or unsuccessful birds could follow successful foragers, and (2) cormorants have more current information on prey availability, so pelicans should benefit by following outgoing cormorants. In contrast to prediction (1), the majority of outbound pelican and cormorant flights initiated at colonies on both lakes were single birds. In addition, outgoing flights were smaller than incoming flights on both lakes. This indicates that group formation at the colony is less frequent, and therefore perhaps less important, than group formation elsewhere that results in larger flocks moving between foraging sites or making return flights to colonies.
Finally, outbound birds sometimes changed flight groups while still in sight of the colony. Therefore, they did not always remain with the group that formed at the colony, and thus they would not benefit from information transfer. These lines of evidence suggest that groups are important for these birds, but they do not support the hypothesis that breeding colonies function as intraspecific information centers. However, when we considered the numbers of birds moving rather than the frequency of flights, more pelicans and cormorants traveled as part of groups than solo. This suggests that despite the frequent occurrence of solo flights, traveling in groups from breeding colonies is important for many birds. Thus, our data on outgoing group size provide at best ambiguous support for the information center hypothesis.

With respect to prediction (2), we found that mixed flights of pelicans and cormorants were relatively rare, comprising only $1.8-2.4 \%$ of all observed flights. Specifically, $1.2-1.6 \%$ of mixed flights were outgoing, suggesting that interspecific information transfer resulting in mixed-species group formation at the colony is not common. Of the outgoing mixed groups that did form, most were led by cormorants $(62-64 \%)$, which is consistent with our prediction that pelicans should follow cormorants to foraging sites. Recent studies of interspecific learning [16, 23-25] suggest that if conspecifics lack certain information, individuals may learn from other species with more knowledge. While previous studies have considered both pelican and cormorant foraging flights individually $[11,14,15]$, this is to our knowledge the first study to address the development of mixed-species foraging flights involving these species. However, we are unable to distinguish whether pelicans followed cormorants in an attempt to find foraging sites, or whether mixed groups formed by chance and cormorants led because they are faster flyers ([15]; personal observations). Regardless, our data show that the large mixed-species foraging aggregations commonly observed on both lakes do not originate at the breeding colonies, and thus are not part of an interspecific information transfer system that uses the colony as a the transfer point.

Although cormorants and pelicans did not typically form large mixed groups while flying outbound from breeding colonies, they frequently foraged in such aggregations. In addition, mixed-species inbound and transit flights were often large. Thus, these birds somehow form groups at foraging sites or other locations removed from breeding colonies. Possible mechanisms for this include birds spotting other foragers while flying overhead, or they may follow the general direction of traffic to and from foraging areas [9, 26]. An alternative is that both species respond to similar cues from habitat or prey, and simply end up in the same foraging locations independently. The amount of open water on both lakes likely permits birds to spot others easily during relatively low-altitude flights, and both colonies were large enough to provide a steady stream of incoming and outgoing birds that might indicate the general direction of good foraging sites. We cannot distinguish between these two possibilities. However, in several pilot experiments (C. Somers et al., unpublished data) we were able to attract pelicans and cormorants to specific locations on Last Mountain Lake by feeding fish to California gulls (Larus californicus), which nested on the same island as the cormorants and pelicans. Pelicans and cormorants were presumably attracted by the 
feeding activities of the gulls, which would provide support for the idea that they may locate foraging sites, at least some of the time, by observing other species, rather than following them per se.

Our hypothesis for information transfer provides an $a$ priori framework to understand potential group formation for outbound flights from breeding colonies, but it does little to explain why inbound birds tended to fly in more regular and larger groups. One possibility is that incoming flights consist of birds returning together from common foraging areas. This explanation seems unlikely given that birds should become satiated at different times while foraging, and therefore return to the colony at different times, not in coordinated groups. In support of the notion that incoming groups are likely not foraging mates, we commonly observed individual cormorants carrying nesting material in returning flocks, which indicates that they did not return directly from a foraging site. In addition, many inbound birds joined groups while in sight of the colony. Thus, it is likely that inbound groups do not necessarily return together from the same foraging site. Group formation in returning flights may be for navigation or communication, but it is unlikely that this is necessary when returning to the breeding colony. Alternatively, returning birds may fly in groups to benefit from the energy savings of flying in formation [27-31]. Provisioning adults make more trips [30] and carry more mass so the cost of flight is greater. This is supported by the flight formations observed during inbound flights (personal observations); groups were typically arranged in column, $\mathrm{V}$, or $\mathrm{J}$ formations [31], which provide more energy savings than flying alone [27-31]. Energy savings may also explain why incoming group sizes tended to be larger during late chickrearing, when adults would be carrying larger and heavier prey to feed their young. In addition, flight groups may also take a while to form, which may explain why large outgoing groups at the colony were relatively uncommon. Other studies $[11,14,32]$ have also reported that American white pelicans and double-crested cormorants tend to leave the colony alone, but can form larger groups, via an unknown mechanism, as they travel.

At both study sites, group sizes for all flights varied during the breeding season. This indicates that the importance of group formation is at least partly determined by reproductive stage. At both lakes, and for both species, flight groups were smallest during egg incubation. We cannot explain the underlying cause of this based on our data, but propose two possible explanations: (1) the lower demand on adult foraging without chicks to feed reduces the need for group formation, or (2) some feature of prey availability in the early part of the season does not require frequent group formation. $\mathrm{Fu}-$ ture studies need to incorporate measures of prey availability and foraging activities of marked birds to clarify this. Inbound and outbound pelican flights at both lakes were largest during late chick rearing, as were cormorant flights at Dore Lake. Thus for some reason this period favors larger groups. Prey may be depleted closer to the colony by late in the chick-rearing period ("Ashmole's halo" [33, 34]), requiring birds to travel farther and fly in formation to save energy, or locate other successful foraging sites. Higher demand to bring food to nearly full-grown young may select for group formation for similar reasons. Cormorant flights at Last Mountain Lake do not fit this explanation, however, as they were largest during early chick rearing. We postulate that because the group sizes were larger during this time, they may have had greater importance for the Last Mountain Lake cormorants during this period. Other studies have shown that group formation in cormorants can be influenced by prey availability, or a decline in underwater visibility [10], both of which may have contributed to the patterns we observed.

\section{CONCLUSION}

The formation of groups of colonial birds for flights may be important for a number of potential reasons: (a) individuals follow more knowledgeable birds to successful foraging sites (the information center hypothesis [5]; e.g., [35, 36]); (b) social or cooperative foraging encourages individuals to travel together to ensure they are part of a group when they arrive at the foraging site [11]; (c) energy savings when flying in formation [28]; (d) navigation and communication [37]; and (e) predator avoidance while flying (although this is not likely an issue for large birds [38]). Pelicans and cormorants are likely candidates to form groups to gain information because they nest in large colonies, and remain at the site for a relatively long time (approximately 17 weeks [39]) to raise altricial young [26]. Also, because they often travel large distances to find ephemeral prey, they may be able to decrease search time by gaining information from others [5]. Our observations over the entire breeding season at two different colonies produced equivocal evidence for the information center hypothesis; outbound flights tended to be solo, but more birds left the colony in groups. Previous studies involving other seabird species (e.g., Alcids [40], Larids [41]) have also been inconclusive regarding this hypothesis. With respect to interspecific information transfer, while cormorants and pelicans sometimes travel and forage together ([8]; personal observations), there is little evidence that mixed foraging groups are initiated at the colony. Thus, group formation in pelicans and cormorants likely occurs most often via another, as yet uncharacterized mechanism that may involve searching for other foraging piscivorous species on lakes.

\section{ACKNOWLEDGMENTS}

This research was funded by Saskatchewan Environment's Fisheries and Wildlife Development Fund and Environment Canada's Canadian Wildlife Service. We thank C. Gaudet, R. Gosselin, H. Miller, G. Sedgewick, and J. Verhagen for assistance in the field; P.S. Taylor, K. R. Hecker, and the staff at the Last Mountain Lake National Wildlife Area and Migratory Bird Sanctuary for facilitating research at that site; and D. and V. Schroh of the Dore Lake Lodge for use of equipment. We thank R.M. Brigham for helpful comments on an earlier version of this manuscript.

\section{REFERENCES}

[1] Alexander RD. The evolution of social behavior. Annu Rev Ecol Syst 1974; 5: 325-83.

[2] Brown CR, Brown MB. Group-living in cliff swallows as an advantage in avoiding predators. Behav Ecol Sociobiol 1987; 21: 97107.

[3] Murphy EC, Schauer JH. Synchrony in egg-laying and reproductive success of neighbouring common murres, Uria aalge. Behav Ecol Sociobiol 1996; 39(4): 245-58. 
[4] Varela SAM, Danchin E, Wagner RH. Does predation select for or against avian coloniality? A comparative analysis. J Evol Biol 2007; 20: 1490-503.

[5] Ward P, Zahavi A. The importance of certain assemblages of birds as "information centres" for food finding. Ibis 1973; 115: 517-34.

[6] Rolland C, Danchin E, de Fraipont M. The evolution of coloniality in birds in relation to food, habitat, predation, and life-history traits: A comparative analysis. Am Nat 1998; 151(6): 514-29.

[7] Richner H, Heeb P. Communal life: honest signaling and the recruitment center hypothesis. Behav Ecol 1996; 7(1): 115-19.

[8] Anderson JGT. Foraging behavior of the American white pelican (Pelecanus erythrorhynchos) in western Nevada. Colonial Waterbirds 1991; 14(2): 166-172.

[9] Glanville, EV. Co-operative fishing by double-crested cormorants, Phalacrocorax auritus. Can Field Nat 1992; 106: 522-23.

[10] van Eerden MR, Voslamber B. Mass fishing by cormorants Phalacrocorax carbo sinensis at Lake Ijsselmeer, the Netherlands: A recent and successful adaptation to a turbid environment. Ardea 1995; 83: 199-212.

[11] O'Malley JBE, Evans RM. Flock formation in white pelicans. Can J Zool 1982; 60: 1024-31.

[12] Johnson RF, Sloan NF. White pelican production and survival of young at Chase Lake National Wildlife Refuge, North Dakota. Wilson Bull 1978; 90: 346-52.

[13] Trottier GC, Breneman RJ, Young NA. Status and foraging distributions of white pelicans, Prince Albert National Park, Saskatchewan. Can Field Nat 1980; 94: 383-90.

[14] O'Malley JBE, Evans RM. Structure and behavior of white pelican formation flocks. Can J Zool 1982; 60: 1388-96.

[15] Custer TW, Bunck C. Feeding flights of breeding double-crested cormorants at two Wisconsin colonies. J Field Ornithol 1992; 63(2): 203-11.

[16] Seppanen J-T, Forsman JT, Monkkonen M, Thomson RL. Social information use is a process across time, space, and ecology, reaching heterospecifics. Ecology 2007; 88(7): 1622-33.

[17] Somers CM, Kjoss VA, Brigham RM. American white pelicans force copulations with nestlings. Wilson J Ornith 2007; 119(2): 279-83.

[18] Sovada MA, King DT, Erickson M, Gray C. Historic and current status of the American white pelican breeding at Chase Lake National Wildlife Refuge, North Dakota. Waterbirds 2005; 28(Special Publication 1): 27-34

[19] Kuiken T. Review of Newcastle disease in cormorants. Waterbirds 1999; 22(3): 333-47.

[20] Leger C, McNeil R. Nest attendance and care of young in doublecrested cormorants. Colon Waterbirds 1985; 8(2): 96-103.

[21] O'Malley JBE, Evans RM. Kleptoparasitism and associated foraging behaviors in American white pelicans. Colon Waterbirds 1983; 6: 126-29.

[22] Derby CE, Lovvorn JR. Predation on fish by cormorants and pelicans in a cold-water river: a field and modeling study. Can J Fish Aquat Sci 1999; 54: 1480-93.
[23] Karplus I, Zion B, Rosenfeld L, et al. Social facilitation of learning in mixed-species schools of common carp Cyprinus carpio L. and Nile tilapia Oreochromis niloticus (L.). J Fish Biol 2007; 71: 102334.

[24] Seppäen J-T, Forsman JT. Interspecific social learning: Novel preference can be acquired from a competing species. Curr Biol 2007; 17: 1248-52.

[25] Forsman JT, Seppanen J-T, Monkkonen, M. Positive fitness consequences of interspecific interaction with a potential competitor. Proc Biol Sci 2002; 269(1500): 1619-23.

[26] Bayer RD. How important are bird colonies as information centers? Auk 1982; 99: 31-40.

[27] Speakman JR, Banks D. The function of flight formations in Greylag Geese Anser anser: Energy saving or orientation? Ibis 1998; 140: $280-7$

[28] Weimerskirch $\mathrm{H}$, Martin J, Clerquin Y, Alexandre P, Jiraskova S Energy saving in flight formation. Nature 2001; 413: 697-8.

[29] Anderson CD, Roby DD, Collis K. Foraging patterns of male and female double-crested cormorants nesting in the Columbia River estuary. Can J Zool 2004; 82: 541-54.

[30] Heppner FH. Avian flight formations. Bird Band 1974; 45: 160-9.

[31] Lissaman PBS, Shollenberger CA. Formation flight of birds. Science 1970; 168: 1003-5.

[32] Bartholomew GA Jr. The fishing activities of double-crested cormorants on San Francisco Bay. Condor 1942; 44: 13-21.

[33] Ashmole NP. The regulation of numbers of tropical oceanic birds. Ibis 1963 ; 103b: 458-73.

[34] Birt VL, Birt TP, Goulet D, Cairns DK, Montevecchi WA. Ashmole's halo: direct evidence for prey depletion by a seabird. Mar Ecol Prog Ser 1987; 40: 205-8.

[35] Waltz EC. A test of the information centre hypothesis in two colonies of common terns. Anim Behav 1987; 35(1): 48-59.

[36] Custer TW, Osborn RG. Feeding habitat use by colonially-breeding herons, egrets, and ibises in North Carolina. Auk 1978. 95(4): 73343.

[37] Cutts CJ, Speakman JR. Energy savings in formation flight of pinkfooted geese. J Exp Biol 1994; 189: 251-61.

[38] Stinson CH. Flocking and predator avoidance: models of flocking and observations on the spatial dispersion of foraging winter shorebirds (Charadrii). Oikos 1980; 34(1): 35-43

[39] Nelson JB Ed. Pelicans, Cormorants, and their Relatives: The Pelecaniformes. Oxford: Oxford University Press; 2005.

[40] Davoren G, Montevecchi WA, Anderson JT. The influence of fish behaviour on search strategies of common murres Uria Aalge in the Northwest Atlantic. Mar Ornithol 2003; 31: 123-31

[41] Andersson M, Gotmark F, Wiklund CG. Food information in the Black-headed Gull Larus ridibundus. Behav Ecol Sociobiol 1981; 9(3): 199-202. 